\title{
Lower treatment targets for gestational diabetes: is lower really better?
}

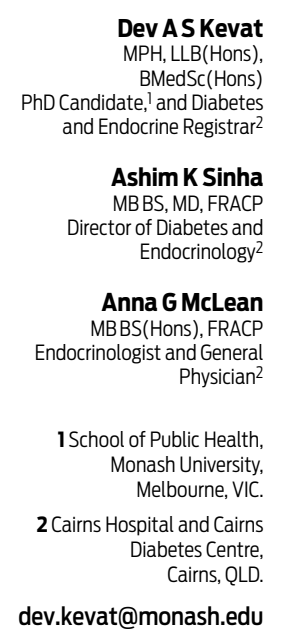

doi: 10.5694/mjal4.00099
T he rationale for management of gestational diabetes mellitus (GDM) is well established - treatment reduces the risk of macrosomia and its attendant complications. This Journal has carried the views of proponents of lower diagnostic and treatment targets for GDM in the context of updated Australian guidelines..$^{1,2}$ In this article, we focus on the costly and potentially deleterious effects of suggested lower treatment targets. We argue that such targets are based on insufficient interventional data, create potential health and medicolegal risks and pose great problems for implementation, particularly to providers in regional and remote areas such as our own health district, which services an area about the size of Victoria. In our view, the disadvantages of lower treatment targets currently outweigh the limited evidence of benefits.

\section{Evidence of risks and benefits to patients}

Three key trials have informed current practice for managing GDM. The Australian Carbohydrate Intolerance Study (ACHOIS), an interventional study of 1000 women enrolled over about 10 years to 2003, used lower diagnostic thresholds as well as lower treatment targets. ${ }^{3}$ Treatment targets were blood sugar level (BSL) of $5.5 \mathrm{mmol} / \mathrm{L}$ (fasting) and $7.0 \mathrm{mmol} / \mathrm{L}$ ( $2 \mathrm{~h}$ postprandial) in the intervention group. These treatment targets are now the standard of care in many Australian centres. The comparator control group caregivers were unaware of the diagnosis of "glucose intolerance of pregnancy" (the prevailing terminology at the time). Further investigation and management by the treating clinician was permitted if indicated. The ACHOIS trial showed a significant improvement in the intervention group for the primary composite fetal outcome measure (death, shoulder dystocia, bone fracture and nerve palsy) with increased rates of induction of labour in mothers and an increased rate of admission of babies to the neonatal nursery. Interestingly, the trial did not show a statistically significant reduction in caesarean section rates.

A smaller trial in the United States studied the effect of treatment of mild hyperglycaemia among women recruited from 2002 to 2007.4 Using a 3-hour $100 \mathrm{~g}$ oral glucose tolerance test, mild GDM was diagnosed if the fasting glucose level was less than $5.3 \mathrm{mmol} / \mathrm{L}$ with two or three timed glucose measurements that exceeded established thresholds of $10.0 \mathrm{mmol} / \mathrm{L}$ at $1 \mathrm{~h}, 8.6 \mathrm{mmol} / \mathrm{L}$ at $2 \mathrm{~h}$, and/or $7.8 \mathrm{mmol} / \mathrm{L}$ at $3 \mathrm{~h}$. Treatment targets of $5.3 \mathrm{mmol} / \mathrm{L}$ (fasting) and $6.7 \mathrm{mmol} / \mathrm{L}$ ( $2 \mathrm{~h}$ postprandial) were then applied to the intervention group. The trial did not show a difference in the chosen primary perinatal composite outcome (perinatal death, neonatal hypoglycaemia, hyperbilirubinaemia, elevated cord C-peptide level, and birth trauma). The rate of

\section{Abstract \\ Proposed lower diagnostic thresholds and lower treatment targets for gestational diabetes have been controversial internationally. \\ Intervention trials for the recently revised lower Australian treatment targets are currently lacking. \\ While there may be benefits, lowering treatment targets may cause a number of harms including increased risk of hypoglycaemia in pregnant women, greater medicolegal risk for health practitioners, and heavier economic costs for the health system. \\ Regional and remote care providers in particular will have greater costs, and may be overwhelmed in attempts to implement new treatment targets. \\ An excessively glucose-centric focus may divert attention and resources from identifying and addressing other important and growing contributors to adverse pregnancy outcomes, such as obesity. \\ Important groups such as Aboriginal and Torres Strait Islander Australians may not gain overall benefit from lowering treatment targets for gestational diabetes because of current low birthweights and the effect of social costs. \\ - It has not yet been established whether implementing lower treatment targets for gestational diabetes will create more benefit than harm. Implementation at this stage is premature.}

induction of labour was not different for the intervention group; and caesarean section and shoulder dystocia rates were reduced. 4

The large observational Hyperglycemia and Adverse Pregnancy Outcome (HAPO) study showed a continuous relationship between fasting, 1-hour and 2-hour glucose levels obtained on a $75 \mathrm{~g}$ glucose tolerance test and the risk of increased birthweight, primary caesarean section, elevated cord C-peptide levels, and neonatal hypoglycaemia. ${ }^{5}$ No obvious threshold where risk overtly increased was found. GDM diagnostic criteria were subsequently revised: it was suggested that a diagnosis of GDM should be made on the basis of blood sugar levels that correlated with a 1.75-fold increased risk of specific fetal measures (birthweight $>90$ th percentile, percentage body fat $>90$ th percentile, and cord C-peptide level $>90$ th percentile). ${ }^{6}$ The HAPO study did not specifically address any ongoing glycaemic measures throughout pregnancy, and the subsequently suggested diagnostic criteria have not been uniformly adopted, owing to concerns and debate outside the scope of this article.

The continuous relationship between increased glucose measures and increased risk of complications presents both a scientific and philosophical challenge - where a continuous 
relationship occurs in medicine there is no firm boundary to the disease entity. The definition of disease is one that the profession decides. We argue that in such areas, interventional data are even more important for establishing cut-off points. Harm to our patients must be captured and weighed against the advantages of further intervention. While there is useful information about normal glycaemic values in pregnancy, ${ }^{7}$ recent articles, including a metaanalysis, have commented that randomised controlled trials (RCTs) showing benefits of intervention in this area were scarce and data quality poor, particularly with regard to postprandial values. ${ }^{8}$

Thus, based on the current uncertain interventional data regarding milder hyperglycaemia, it would seem difficult to support treatment thresholds being reduced even further to $5.0 \mathrm{mmol} / \mathrm{L}$ fasting, $7.4 \mathrm{mmol} / \mathrm{L}$ at $1 \mathrm{~h}$ and $6.7 \mathrm{mmol} / \mathrm{L} 2$ hours after meals for Australian women. ${ }^{2}$ These targets (Box 1) are arguably the most aggressive in the world. Indeed, Nankervis and colleagues state that such targets should, ideally, be examined by RCTs. ${ }^{13}$ We would greatly prefer such interventional studies be conducted and prove overall benefit before adoption of the revised targets.

It is noteworthy and problematic that a fasting BSL less than $5 \mathrm{mmol} / \mathrm{L}$ also conflicts with current Diabetes Australia advice that patients on insulin should have a BSL "above 5 to drive"; 14 no driving before breakfast may not be practical for some women.

We are concerned that a treatment target of $5.0 \mathrm{mmol} / \mathrm{L}$ fasting will expose women to the risk of hypoglycaemia, particularly given that current international standards for blood sugar monitors allow for a $15 \%$ error margin (ie, a BSL of $4.0 \mathrm{mmol} / \mathrm{L}$ could be $3.4-4.6 \mathrm{mmol} / \mathrm{L}$ ). Indeed, in a recent study, a fifth of monitors tested failed the looser standard of a $20 \%$ error margin, and half of meters would have failed the new $15 \%$ standard without improvements. ${ }^{15}$ In addition, it is noteworthy that neither the observational HAPO study nor the interventional trial of mild GDM reported maternal hypoglycaemia as an outcome and that overtreatment could potentially lead to an increase in small-for-gestational-age babies among women at risk of placental insufficiency. ${ }^{16}$

\section{Medicolegal risk and clinical judgement in the real world}

Guidelines often allude to notions of clinician judgement as the ultimate authority for patient care. ${ }^{2}$ Such statements are understandable but can be wishful, particularly in relation to GDM. Many women with GDM will not be seen by specialists, who have greater training in a specific area, better access to diagnostic services (such as ultrasound for determining growth rates) and would be more willing to depart from guidelines. It has been estimated that the new diagnostic criteria will lead to a $35 \%$ increase in the number of women diagnosed with GDM. ${ }^{17}$ Most women will thus be predominantly cared for by diabetes educators, midwives, nurses and general practitioners. This is particularly true in regional and remote areas where specialists are scarce. For reasons of workload and workforce, management of GDM is likely to become even more driven by protocols, adding weight to the importance of guidelines being both workable and correct.

While in Australia it is ultimately courts that determine what constitutes negligent conduct, the opinion of medical experts is persuasive, ${ }^{18}$ and new lower targets are likely to become the default new standard of care. In practice, many health practitioners will struggle to achieve these targets with many of their patients. Given the large number of women who will be diagnosed with GDM, the range of neonatal medical conditions that can be linked with GDM and the great expectations that accompany pregnancy, a number of adverse outcomes could be litigated in the future. A reduction in the degree of legal protection for Australian health practitioners may be an unfortunate unintended consequence of lower treatment targets that depart from international practice (Box 1).

The Australasian Diabetes in Pregnancy Society (ADIPS) treatment targets are listed as "suggestions" rather than "recommendations". ${ }^{2}$ However, it is plausible that health practitioners will refer to the new ADIPS guidelines without appreciating the difference between the two. With the bewildering pace of medical advances in many fields, most health practitioners are dependent on expert guidelines to provide direction in clear terms.

\section{Human resource and economic cost}

The human and economic resources required to manage gestational diabetes are considerable. In the Australian setting, such care is resource intensive and often provided by a multidisciplinary approach that may involve GPs, physicians, obstetricians, midwives, nurses, dietitians and diabetic educators. Education and frequent clinical review are the standard of care. The predicted 35\% increase in the number of women diagnosed with GDM will lead to a $13 \%$ prevalence of the disease $\mathrm{e}^{17,19}$ — all women should receive diabetes and dietary education and will require continued review until birth.

Regional centres like our own often serve not just the immediate town but also support remote towns and communities dotted across a vast area. Most women in our

\begin{tabular}{|c|c|c|c|}
\hline Guideline & Fasting & 1h after meals & $2 \mathrm{~h}$ after meals \\
\hline Fifth International Workshop-Conference on Gestational Diabetes Mellitus ${ }^{9}$ & $5.2 \mathrm{mmol} / \mathrm{L}$ & $7.7 \mathrm{mmol} / \mathrm{L}$ & $6.6 \mathrm{mmol} / \mathrm{L}$ \\
\hline Canadian Diabetes Association10 & $5.2 \mathrm{mmol} / \mathrm{L}$ & $7.7 \mathrm{mmol} / \mathrm{L}$ & $6.6 \mathrm{mmol} / \mathrm{L}$ \\
\hline UK National Institute for Health and Clinical Excellencell & $5.9 \mathrm{mmol} / \mathrm{L}$ & $7.7 \mathrm{mmol} / \mathrm{L}$ & Not specified \\
\hline US Endocrine Society12 & $5.3 \mathrm{mmol} / \mathrm{L}$ or $5.0 \mathrm{mmol} / \mathrm{L}^{*}$ & $7.8 \mathrm{mmol} / \mathrm{L}$ & $6.7 \mathrm{mmol} / \mathrm{L}$ \\
\hline Australasian Diabetes in Pregnancy Society² & $5.0 \mathrm{mmol} / \mathrm{L}$ & $7.4 \mathrm{mmol} / \mathrm{L}$ & $6.7 \mathrm{mmol} / \mathrm{L}$ \\
\hline
\end{tabular}


2 Effect of lower treatment targets on a GDM cohort in a major regional centre*

Cairns Hospital cohort ( $n=319$, July 2012 - July 2013)

Current practice: $5.5 \mathrm{mmol} / \mathrm{L}$ (fasting) and $7.0 \mathrm{mmol} / \mathrm{L}$ ( $2 \mathrm{~h}$ postprandial)

Able to be managed with diet and lifestyle control

Required/would require commencement of pharmacotherapy

Already on pharmacotherapy when referred
$183(57 \%)$

$67(21 \%)$

$69(22 \%)$
Proposed practice: $5.0 \mathrm{mmol} / \mathrm{L}$ (fasting) and $6.7 \mathrm{mmol} / \mathrm{L}$ ( $2 \mathrm{~h}$ postprandial)

$122(38 \%)$

$128(40 \%)$

$69(22 \%)$

GDM = gestational diabetes mellitus. *Ethics approval was granted by the Cairns and Hinterland Health Service District for gathering of the audit data.

centre receive 2 hours of education followed by weekly phone or email contact and regular visits, increasing in frequency until the birth. Women who require treatment with insulin need further intensive education and may have to travel considerable distances to gain this. They usually have more frequent antenatal cardiotocography and ultrasound monitoring, done in a major centre. The baby must be born at a tertiary centre, and labour is usually induced at around 38-39 weeks' gestation, leading to an earlier delivery date than for women who are "diet controlled". Neonates are observed in a special care baby unit overnight.

Many of our patients from rural and remote communities must move to live near our hospital in the last month of pregnancy, at considerable cost to themselves and their families. The non-medical cost borne by our hospital system for transport and accommodation alone for the last weeks of pregnancy is at least $\$ 6000$ per patient.

Cost-effectiveness research has been rather limited. An older Australian study with different diagnostic criteria and treatment targets compared the intervention group to a routine care group who were not made aware of their diagnosis, and thus, the study is of limited applicability to the current clinical context. ${ }^{20}$ More recent research concluded that the treatment of milder GDM would not be cost-effective if the cost was greater than US\$3555 compared to a baseline cost of US\$1786 in the different context of the US health system. ${ }^{21}$

In our region of Australia, a diagnosis of GDM triggers a series of events that shifts care away from peripheral centres to our own tertiary care facility. We doubt this situation is unique, and it creates a number of deleterious social consequences for women in their separation from their full support structures and families. For our Aboriginal and Torres Strait Islander and remote patients, these social and psychological effects should not be taken lightly.

While the effect of new diagnostic criteria has been studied, there is a paucity of data on the effect of new treatment targets. In our centre, the decision to commence pharmacotherapy for GDM is made by endocrinology consultants or advanced trainees. In our prospective audit of 319 patients at our major regional centre over 12 months, we treated women according to our current targets of $5.5 \mathrm{mmol} / \mathrm{L}$ (fasting) and $7.0 \mathrm{mmol} / \mathrm{L}$ ( $2 \mathrm{~h}$ postprandial), but simultaneously considered what treatment would have been required to treat to targets of $5.0 \mathrm{mmol} / \mathrm{L}$ and $6.7 \mathrm{mmol} / \mathrm{L}$. Adopting such a practice would have led to a doubling of patients who needed to start pharmacotherapy by our service (Box 2), with $62 \%$ of all women in our clinic requiring pharmacotherapy during pregnancy. Insulin is still the usual first-line treatment in Australia; and studies show that $50 \%$ of patients placed on metformin will additionally need insulin to reach targets. ${ }^{22}$ While it is extremely important that pregnant women are treated optimally, if only $38 \%$ of our patients can be managed with diet alone, this will place considerable burden on our already stretched health system. An excessive glucose-centric focus on treating milder GDM may distract from systematically growing contributors to adverse pregnancy outcomes. Obese patients who do not have GDM are contributing to a greater degree to adverse outcomes. ${ }^{23}$ These factors need to be taken into consideration to avoid misallocation of resources.

\section{Risk of widening the health gap for Aboriginal and Torres Strait Islander Australians}

There is some evidence that exposure to hyperglycaemia in utero is linked to an increased risk of developing type 2 diabetes mellitus later in life, ${ }^{24}$ and, consequently, it has been theorised that management of GDM will reduce this risk. It should be noted that there are no such results from interventional data yet, as these studies take many years to complete. A study of the children of women in the ACHOIS intervention group did not show any reduction in their body mass index at 5 years. ${ }^{25}$

On the other hand, there is considerable evidence that children of low birthweight also have an increased risk of developing type 2 diabetes. In this group of babies, including in specific studies of North American indigenous populations, the lower the birthweight the greater the chance of developing type 2 diabetes later in life. ${ }^{26,27}$ Despite high rates of maternal diabetes, babies of Aboriginal and Torres Strait Islander descent have twice the risk of being of low birthweight $(<2.5 \mathrm{~kg})$ compared with the national average (12\% v 6\%). ${ }^{28}$ It is unclear whether aiming for a lower birthweight with decreased adipose levels among the Aboriginal and Torres Strait Islander population is healthier than a more normal birthweight. Given the prevalence of low birthweight babies in Aboriginal and Torres Strait Islander populations, many of the benefits of GDM treatment, which are largely mediated through reducing macrosomia, may not occur. The high social and economic costs of GDM treatment at lower thresholds certainly will.

The World Health Organization has noted that the lack of ethnically specific data is a limitation of applying knowledge from the HAPO study, and that adaptation may be required for different ethnic groups. ${ }^{29}$ While the Aboriginal and Torres Strait Islander population is numerically small, this group deserves strong consideration given their heavy disease burden and disadvantage. The variation in macrosomia that occurs among Aboriginal and Torres Strait Islander babies as a result of GDM may also occur among babies of women from different ethnic backgrounds in our 
increasingly multicultural country, in which more than a quarter of people were born overseas. ${ }^{30}$

\section{Conclusion}

Although the relationship between maternal blood glucose levels and the risk of macrosomia is a continuous one, there is currently a lack of interventional data to support treatment of GDM to lower targets. To date, studies have not sought to capture the effects of possible maternal hypoglycaemia with lower treatment targets. Some of Australia's recently revised treatment targets are lower than international practice and impose particular social and economic costs while having limited benefits for Aboriginal and Torres Strait Islander Australians. Neither cost-effectiveness nor safety has been established. In our view, an overall analysis of the advantages and disadvantages of lower treatment targets for GDM in Australia suggests that implementation at this stage is premature.

Acknowledgements: We acknowledge the assistance of Susan Caddaye in data collection and processing. Dev Kevat also acknowledges Darryl Finkton and Simon Quinn for helpful conversations regarding determinations of normalcy and disease.

Competing interests: Ashim Sinha is an investigator in the TECOS study (Merck, NCT0790205) and the sitagliptin in children study (Merck, NCT01485614). He is on the speaker bureaux for the Astra Zeneca BMS alliance, Sanofi Aventis, Eli Lilly, Novo Nordisk, Merck, Takeda, Servier and Novartis, and is a member of the Australian medical advisory boards of the Astra Zeneca BMS alliance and Sanofi Aventis. Dev Kevat was sponsored by Astra Zeneca to attend the 2014 American Diabetes Association Scientific Sessions and a 2-day workshop at the Joslin Diabetes Centre, Harvard University, with content being solely decided and presented by Joslin physicians.

Provenance: Not commissioned; externally peer reviewed.

1 McIntyre HD, Oats JJ. Gestational diabetes needs to be managed. Med J Aust 2013; 198: 78-79.

2 Nankervis A, McIntyre HD, Moses R, et al; Australasian Diabetes in Pregnancy Society. ADIPS consensus guidelines for the testing and diagnosis of gestational diabetes mellitus in Australia. 2013. http://www. adips.org/downloads/ADIPSConsensusGuidelinesGDM-03.05.13VersionAC CEPTEDFINAL_000.pdf (accessed Jul 2014).

3 Crowther CA, Hiller JE, Moss JR, et al; Australian Carbohydrate Intolerance Study in Pregnant Women (ACHOIS) Trial Group. Effect of treatment of gestational diabetes mellitus on pregnancy outcomes. N Engl J Med 2005 352: 2477-2486.

4 Landon MB, Spong CY, Thom E, et al; Eunice Kennedy Shriver National Institute of Child Health and Human Development Maternal-Fetal Medicine Units Network. A multicenter, randomized trial of treatment for mild gestational diabetes. N Engl J Med 2009; 361: 1339-1348. doi: 10.1056/ NEJMoa0902430.

5 Metzger BE, Lowe LP, et al; HAPO Study Cooperative Research Group. Hyperglycemia and adverse pregnancy outcomes. N Engl J Med 2008; 358 : 1991-2002. doi: 10.1056/NEJMoa0707943.

6 Metzger BE, Gabbe SG, Persson B, et al; International Association of Diabetes and Pregnancy Study Groups Consensus Panel. International Association of Diabetes and Pregnancy Study Groups recommendations on the diagnosis and classification of hyperglycemia in pregnancy. Diabetes Care 2010; 33: 676-682.

7 Hernandez TL, Friedman JE, Van Pelt RE, Barbour LA. Patterns of glycemia in normal pregnancy: should the current therapeutic targets be challenged? Diabetes Care 2011; 34: 1660-1668. doi: 10.2337/dc11-0241.

8 Prutsky GJ, Domecq JP, Sundaresh V, et al. Screening for gestational diabetes: a systematic review and meta-analysis. J Clin Endocrinol Metab 2013; 98: 4311-4318. doi: 10.1210/jc.2013-2460.

9 Metzger BE, Buchanan TA, Coustan DR, et al. Summary and recommendations of the Fifth International Workshop-Conference on
Gestational Diabetes Mellitus. Diabetes Care 2007; 30 Suppl 2: S25I-S260. doi: $10.2337 / \mathrm{dc} 07-$ s225.

10 Canadian Diabetes Association Clinical Practice Guidelines Expert Committee. Diabetes and pregnancy. http://guidelines.diabetes.ca/ Browse/Chapter36 (accessed Nov 2013).

11 National Institute for Health and Care Excellence. Diabetes in pregnancy: management of diabetes and its complications from pre-conception to the postnatal period. Clinical guideline 63. 2008. http://www.nice.org.uk/ guidance/CG63 (accessed Nov 2013).

12 Blumer I, Hadar E, Hadden DR, et al. Diabetes and pregnancy: an endocrine society clinical practice guideline. J Clin Endocrinol Metab 2013; 98 . 4227-4249. doi: 10.1210/jc.2013-2465.

13 Nankervis A, McIntyre HD, Moses RG, et al. Testing for gestational diabetes mellitus in Australia. Diabetes Care 2013; 36: e64. doi: 10.2337/dcl2-2345.

14 Diabetes and Driving Working Party. Diabetes and driving. Australian Diabetes Society; 2011. http://diabetessociety.com.au/downloads/Driving and Diabetes Booklet.pdf (accessed Jul 2014).

15 Freckmann G, Schmid C, Baumstark A, et al. System accuracy evaluation of 43 blood glucose monitoring systems for self-monitoring of blood glucose according to DIN EN ISO 15197. J Diabetes Sci Technol 2012; 6: 1060-1075.

16 Langer O, Levy J, Brustman L, et al. Glycemic control in gestational diabetes mellitus -- how tight is tight enough: small for gestational age versus large for gestational age? Am J Obstet Gynecol 1989; 161: 646-653.

17 Moses RG, Morris GJ, Petocz P, et al. The impact of potential new diagnostic criteria on the prevalence of gestational diabetes mellitus in Australia. Med J Aust 2011; 194: 338-340.

18 Rogers v Whitaker (1992) 175 CLR 479.

19 Sacks DA, Hadden DR, Maresh M, et al. Frequency of gestational diabetes mellitus at collaborating centers based on IADPSG consensus panelrecommended criteria: the Hyperglycemia and Adverse Pregnancy Outcome (HAPO) Study. Diabetes Care 2012; 35: 526-528.

20 Moss JR, Crowther CA, Hiller JE, et al; Australian Carbohydrate Intolerance Study in Pregnant Women Group. Costs and consequences of treatment for mild gestational diabetes mellitus -- evaluation from the ACHOIS randomised trial. BMC Pregnancy Childbirth 2007; 7: 27.

21 Ohno MS, Sparks TN, Cheng YW, Caughey AB. Treating mild gestational diabetes mellitus: a cost-effectiveness analysis. Am J Obstet Gynecol 2011; 205: 282.el-e7. doi: 10.1016/j.ajog.2011.06.051.

22 Rowan JA, Hague WM, Gao W, et al; MiG Trial Investigators. Metformin versus insulin for the treatment of gestational diabetes. NEngl J Med 2008; 358: 2003-2015. doi: 0.1056/NEJMoa0707193.

23 Black MH, Sacks DA, Xiang AH, Lawrence JM. The relative contribution of prepregnancy overweight and obesity, gestational weight gain, and IADPSG-defined gestational diabetes mellitus to fetal overgrowth. Diabetes Care 2013; 36: 56-62. doi: 10.2337/dc12-0741.

24 Dabelea D. The predisposition to obesity and diabetes in offspring of diabetic mothers. Diabetes Care 2007; 30 Suppl 2: S169-S174. doi: 10.2337/ dc07-s211.

25 Gillman MW, Oakey H, Baghurst PA, et al. Effect of treatment of gestational diabetes mellitus on obesity in the next generation. Diabetes Care 2010; 33: 964-968. doi: 10.2337/dc09-1810.

26 Barker DJ, Hales CN, Fall CH, et al. Type 2 (non-insulin-dependent) diabetes mellitus, hypertension and hyperlipidaemia (syndrome X) relation to reduced fetal growth. Diabetologia 1993; 36: 62-67.

27 Whincup PH, Kaye SJ, Owen CG, et al. Birth weight and risk of type 2 diabetes: a systematic review. JAMA 2008; 300: 2886-2897. doi: 10.1001/ jama.2008.886.

28 Li Z, Zeki R, Hilder L, Sullivan EA. Australia's mothers and babies 2010. Canberra: Australian Institute of Health and Welfare, 2012. (AlHW Cat. No. PER 57; Perinatal Statistics Series No. 27.) http://www.aihw.gov.au/ publication-detail/?id=60129542376 (accessed Jul 2014).

29 World Health Organization. Diagnostic criteria and classification of hyperglycaemia first detected in pregnancy. Geneva: WHO, 2013. http:// apps.who.int/iris/bitstream/10665/85975/1/WHO_NMH_MND_13.2_eng. pdf (accessed Nov 2013).

30 Australian Bureau of Statistics. Reflecting a nation: stories from the 2011 Census, 2012-2013. Canberra: ABS, 2012. (ABS Cat. No. 2071.0.) http:// www.abs.gov.au/ausstats/abs@.nsf/Lookup/2071.0main+featur es902012-2013 (accessed Nov 2013). 